\title{
Measurement of Viscosity Alteration for Emulsion and Numerical Simulation on Bitumen Production by SAGD Considering In-situ Emulsification
}

\author{
Junpei Kumasaka ${ }^{1}$, Kyuro Sasaki ${ }^{1}$, Yuichi Sugai ${ }^{1}$, Olalekan S. Alade ${ }^{1}$ and Masanori Nakano ${ }^{2}$ \\ 1. Department of Earth Resources Engineering, Kyushu University, Fukuoka 819-0395, Japan \\ 2. Research Center, Japan Petroleum Exploration Co., Ltd., Chiba 261-0025, Japan
}

\begin{abstract}
A thermal steam stimulation process, such as steam-assisted gravity drainage (SAGD), induces water-in-oil emulsion of heavy oil or bitumen throughout the production. The present study investigated the effects of in-situ emulsification in the oil sands reservoir for SAGD process. The viscosities of water-in-oil emulsions produced were measured with respect to water-oil ratio (W/O), shear rates, pressures and temperatures. The results therefore were employed to develop the numerical model of viscosity alteration. Numerical simulations of the SAGD bitumen production considering viscosity alteration were also carried out to investigate distribution characteristics of emulsion, water, and bitumen at steam chamber boundary and effects of in-situ emulsification on bitumen production behavior. With a model named SAGD-Emulsion Model, it was found that the net recovery factor of bitumen for this model is 5 to $10 \%$ higher than that of conventional SAGD simulation. Ultimately, it was found that the recovery factor of bitumen increased with W/O of emulsion generated in the reservoir since higher water content would invariably allow bitumen to flow at higher relative permeability, while the increase in viscosity merely delayed bitumen production.
\end{abstract}

Key words: Viscosity alteration, bitumen, emulsion, in-situ emulsification, SAGD.

\section{Introduction}

Canada has the third largest of oil reserves in the world due to its huge amount of oil sands resources. The oil reserves are being estimated as about 173 billion barrels with most of them located in Western Canada. Two general categories of techniques, including open pit mining and in-situ recovery, are applied in production of bitumen from oil sands. One of the most successful thermal in-situ methods is steam-assisted gravity drainage (SAGD); and has been employed in commercial production of bitumen from oil sands reservoir [1,2]. The API gravity of bitumen is less than $10^{\circ}$ and its mobility at initial reservoir temperature is nearly equal to zero. In SAGD method, two parallel horizontal wells are used as injector and producer; with steam injection into the reservoir from the injector which heats bitumen to decrease its

Corresponding author: Junpei Kumasaka, M.S. in engineering, research field: petroleum production engineering. viscosity (typically from order of $10^{6} \mathrm{cP}$ to less than $10 \mathrm{cP})$. Subsequently, heated oil and steam condensate are produced simultaneously from lower producer by gravity force (see Fig. 1).

Some experimental studies on SAGD process have been conducted by independent researchers. Furthermore, numerical modeling of effective phenomena observed in these experiments and application to commercial field receive attention from some researches. An excellent review of current status and future issues on SAGD was presented by Al-Bahlani and Babadagli [1] in terms of experimental and numerical studies. As mentioned in their review, Sasaki et al. [3] suggested the in-situ emulsification mechanism in the SAGD process as shown in Fig. 1.

Generally, when a thermal fluid such as steam is injected into an oil reservoir, condensation of steam is generated with steam releasing its latent heat to the oil and rock matrix. In addition, the surface action of oil 


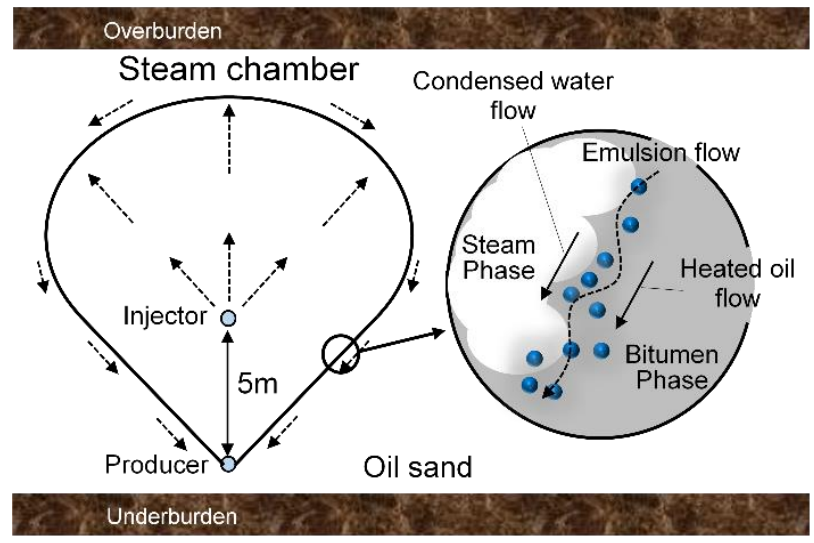

Fig. 1 Mechanism of SAGD process and in-situ emulsification modified from Sasaki et al. [3].

components, such as asphaltene and resins, are instigated; and this leads to formation of emulsion which could exhibit remarkable increase in apparent viscosity and non-Newtonian behavior [4, 5]. Throughout the SAGD process, bitumen is typically produced as water-in-oil (W/O) emulsion in the field which is often very stable; and of viscosity higher than the viscosity of original oil $[6,7]$.

Fig. 2 shows a typical W/O emulsion produced from SAGD well in Hangingstone, Canada. As evident through some previous experimental studies on this phenomenon [3, 6, 8-11], it has been suggested that $\mathrm{W} / \mathrm{O}$ emulsions are mostly produced during the SAGD process. Especially, Sasaki et al. [8, 9] conducted experimental studies of SAGD process by using two-dimensional scaled reservoir model to investigate fluids flow characteristics in the steam chamber. Furthermore, they also carried out visualization of micro-phenomena at inclined interface on the side of steam chamber by means of a high-resolution optical-fiber scope [3]. In this experiment, very fine droplets were observed at the interface between steam and heavy crude oil phase. They assumed that very fine water droplets generated on cold oil surface entered into oil phase just after generation and released their heat into the oil phase (i.e. some water droplets became condensed water). Thus, it is inferred that gravitational flow of emulsion exists between condensed water and heated oil.

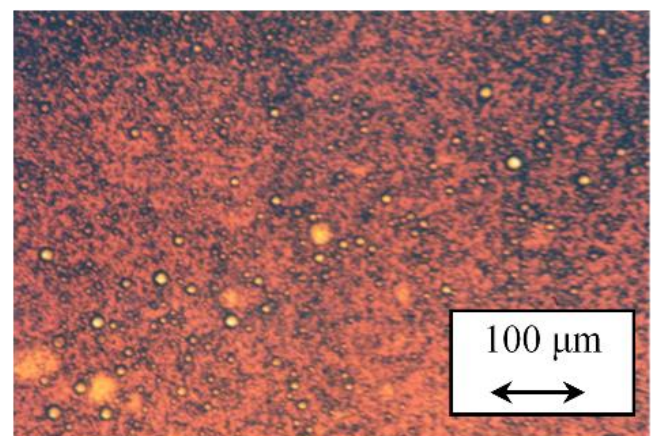

Fig. 2 Photomicrographs of bitumen emulsion produced from SAGD well at Hangingstone operated by JACOS.

As earlier discussed, however, the viscosity of emulsion is quite higher than that of original oil. Therefore, viscosity alteration with in-situ emulsification may affect gravitational flow of produced fluids and their production behavior.

In this study, viscosity of emulsions that were formed by injecting steam into heavy oil was measured with respect to W/O at different shear rates, pressures and temperatures and was compared with that of bitumen emulsion. Based on these results, a numerical model of viscosity alteration by emulsion generation was developed for SAGD process. The distribution characteristics of emulsion, water and bitumen at the steam chamber boundary and effects of emulsion generation on bitumen production behavior were also investigated by means of commercial reservoir simulator, CMG STARS ${ }^{\mathrm{TM}}$.

\section{Experimental Samples and Apparatus}

Experiments were performed at different conditions to investigate the effects of degree of emulsification on viscosity alteration. In this experiment, water-in-oil emulsions were formed by using a heavy crude oil (Hokkaido, Japan) and Canadian bitumen. Their representative properties are shown in Table 1.

Water-in-oil emulsions with different $\mathrm{W} / \mathrm{O}$ ratio were generated by injecting steam into heavy oil samples using steam generator (Yamazen, YSC-130). Bitumen emulsion was also generated at $200{ }^{\circ} \mathrm{C}$ and $2 \mathrm{MPa}$ by using high-pressure micro-reactor (OM 

SAGD Considering In-situ Emulsification

Table 1 Representative characteristics of oil samples used in the experiments.

\begin{tabular}{lll}
\hline Characteristics & Heavy oil & Bitumen \\
\hline Place of production & Japan & Canada \\
Density $\left(\mathrm{g} / \mathrm{cm}^{3}\right)$ & $0.998\left(@ 15^{\circ} \mathrm{C}\right)$ & $1.016\left(@ 15^{\circ} \mathrm{C}\right)$ \\
API gravity $\left({ }^{\circ}\right)$ & 11.6 & 7.6 \\
Kinetic viscosity $(\mathrm{cSt})$ & $874\left(@ 30^{\circ} \mathrm{C}\right)$ & $6970\left(@ 50{ }^{\circ} \mathrm{C}\right)$ \\
\hline
\end{tabular}

Fig. 3 Viscosity measurement apparatus for high pressure and temperature.

Labtech, MMJ-50). Plumbing type viscosity sensor (Cambridge Viscosity, Model SPL372) was plumbed in high temperature oven as illustrated in Fig. 3 and used to measure the viscosity of these emulsions at high pressure and temperature. A rotational type viscometer (Brookfield, Model DV-III) was also used to investigate the effects of shear rate on viscosity alteration.

\section{Results and Discussion}

\subsection{Emulsion Characteristics}

Figs. 4 and 5 show photomicrographs of each generated emulsion. Volume frequency distributions for water droplets diameter were also calculated from these pictures as shown in Figs. 6 and 7. In heavy oil emulsions, the average diameter of the droplets was found to increase with W/O as shown in Figs. 4 and 6. The distribution range of the water droplets diameter in bitumen emulsion, which was formed by using micro-reactor, was from 2 to $14 \mu \mathrm{m}$, which are close to the value reported in the field.

However, the average particle size is larger than that of emulsion produced in the field. The difference is believed to be inherent to the process of emulsification. Previous studies in this aspect have reported that the extent of emulsification, which is very much connected with the particle size, is dependent to the parameter such as formation temperature $[4,7]$. In fact, condensed water droplets generated from steam enter into bitumen phase and form emulsions in SAGD process. The temperature of injected steam during SAGD process is more than $250{ }^{\circ} \mathrm{C}$, while bitumen emulsion was generated at $200{ }^{\circ} \mathrm{C}$ and $2 \mathrm{MPa}$ (i.e. formation pressure is higher than saturation

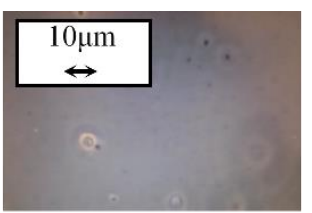

$\mathrm{W} / \mathrm{O}=0$ (original oil)

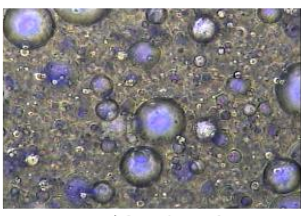

$\mathrm{W} / \mathrm{O}=0.56$

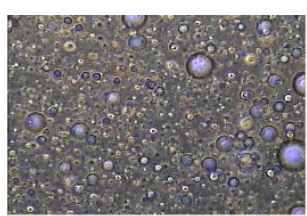

$\mathrm{W} / \mathrm{O}=0.25$

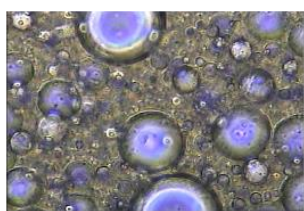

$\mathrm{W} / \mathrm{O}=0.74$
Fig. 4 Photomicrographs of heavy oil emulsions.

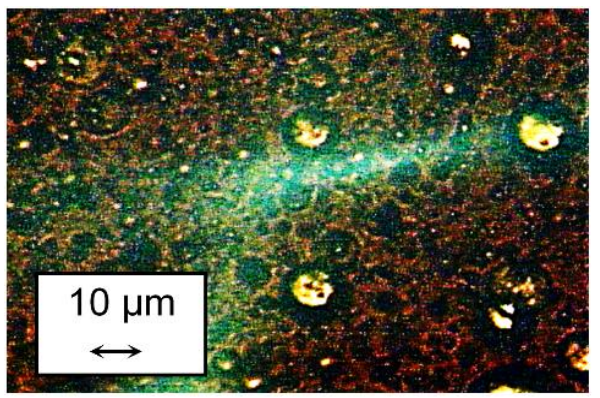

Fig. 5 Photomicrographs of bitumen emulsion (W/O = 0.25).

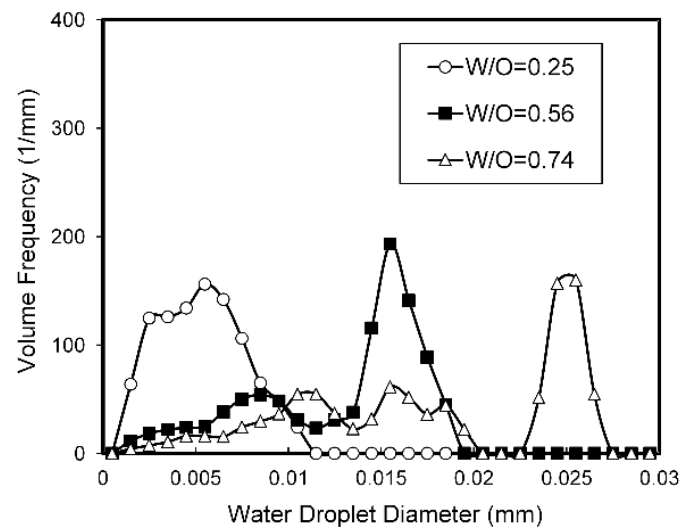

Fig. 6 Diameter distribution of water droplets in heavy oil emulsion formed by injecting steam. 


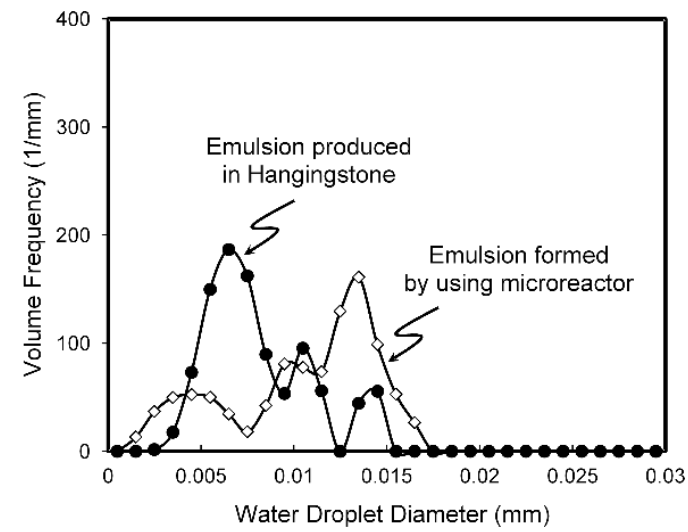

Fig. 7 Diameter distribution of water droplets in bitumen emulsion formed by using microreactor.

pressure at $200{ }^{\circ} \mathrm{C}$ ) in this experiment. Another plausible explanation is the assumption that emulsions generated during SAGD process flow down by gravity and go through pore throats of sandstone. Therefore, larger water droplets are expected to break before reaching to producer well. However, it is expected that the effect of very small droplets on viscosity is negligible.

\subsection{Viscosity Measurement}

The viscosity-temperature relationships of heavy crude oil and bitumen under present investigation are compared in Fig. 8. It shows that the viscosity of bitumen is one or two order higher than that of heavy crude oil at the same temperature. However, the decline curves both heavy crude oil and bitumen followed similar trend. For instance, reduction in viscosity of heavy crude oil between $30^{\circ} \mathrm{C}$ and $50{ }^{\circ} \mathrm{C}$ corresponds to that of bitumen between $80{ }^{\circ} \mathrm{C}$ and $100{ }^{\circ} \mathrm{C}$. In this experiment, viscosity measurements were carried out in these temperature ranges respectively. In other words, viscosity range is almost same in both heavy crude oil and bitumen during experiments.

The viscosity alteration behavior of emulsion is affected by many factors, including chemical composition of crude oil, temperature, viscosity of oil and water, surfactant components, droplet size and shear rate. Fig. 9 shows the result of viscosity measurements of heavy oil emulsions by using the rotational type viscometer. Apparent viscosity of generated emulsions was observed to increase with W/O ratio. This observation is susceptibly due to the increase in droplet-droplet interaction as the number of water droplets increases. This result agreed with that of Maneeintr et al. [12]. The differences of apparent viscosity, that depends on shear rate, were observed clearer as W/O became higher. However, viscosity alteration that was affected by shear rate was much smaller than that caused by W/O, especially within 0.6 of W/O. Uzoigwe [13] and later Alvarado and Marsden [14] stated that Newtonian behavior was observed for entire range of shear rate until dispersed-phase concentration reached about $50 \mathrm{vol} \%$ or more. Therefore, it is assumed that apparent viscosity alteration of the emulsion is mainly determined by W/O.

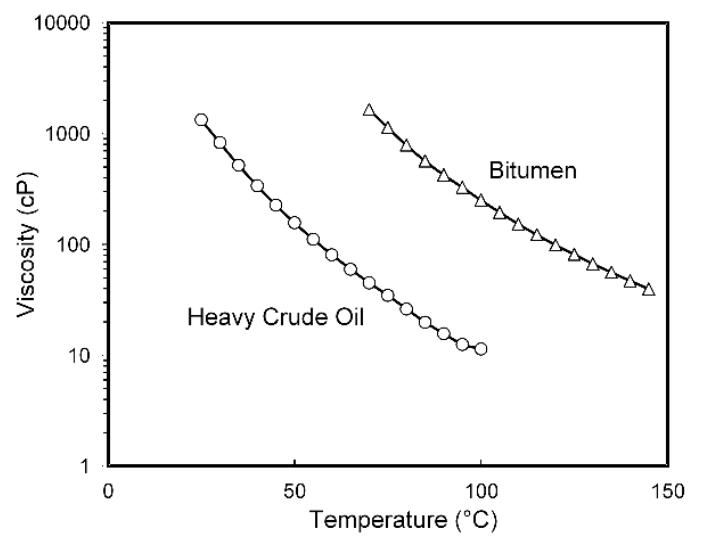

Fig. 8 Viscosity of heavy oil and bitumen versus temperature.

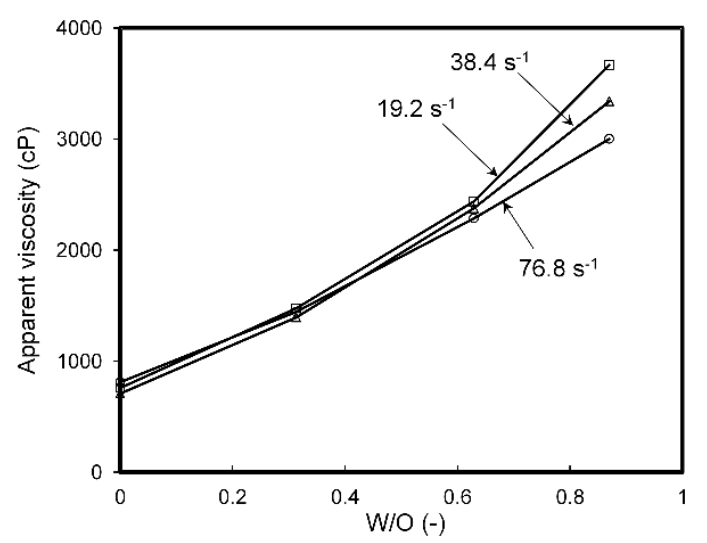

Fig. 9 Relationship of apparent viscosity vs. W/O at different shear rate (heavy oil). 


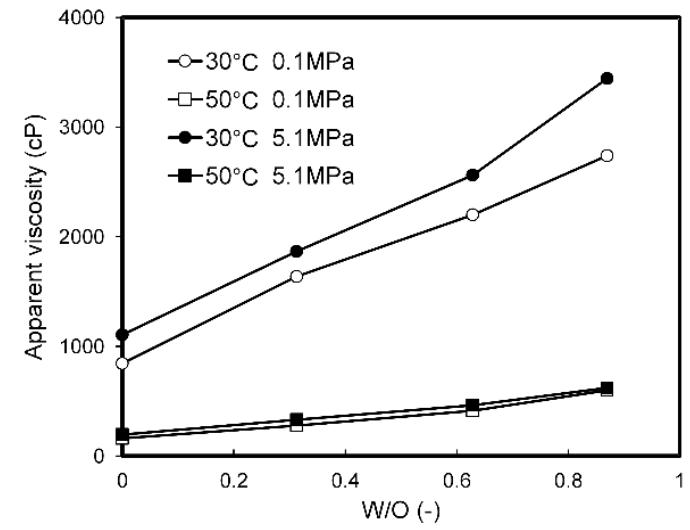

Fig. 10 Relationship of apparent viscosity vs. W/O at different pressure and temperature (heavy oil).

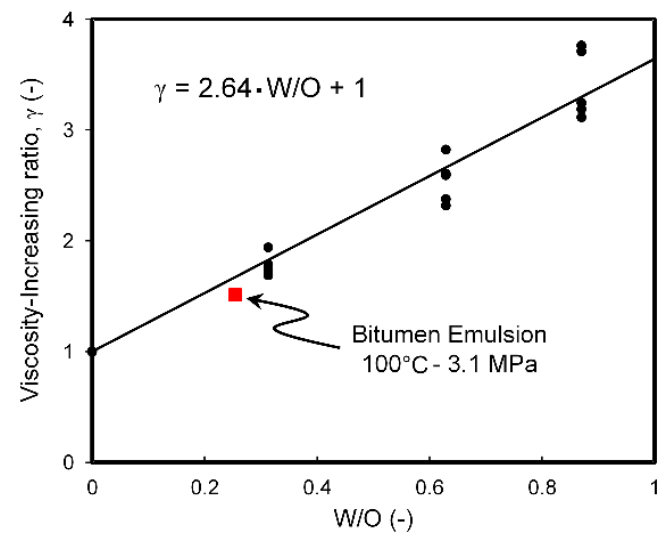

Fig. 11 Relationship of viscosity-increasing ratio vs. W/O (heavy oil) and comparison with bitumen emulsion.

Furthermore, as shown in Fig. 10, viscosity of emulsions with different W/O ratio was measured at high pressure and temperature to investigate effects of temperature and pressure on viscosity alteration. Viscosity-increasing ratio $\gamma$, which was defined by Eq. (1), was also plotted as shown in Fig. 11.

$$
\gamma=\frac{\text { Apparent viscosity of emulsion }}{\text { Apparent viscosity of original oil }}
$$

It can be observed from this figure that apparent viscosity increased with increasing pressure and decreased with rise in temperature. Accordingly, $\gamma$ increased linearly with W/O. In comparison, an experimental result of bitumen emulsion at $100{ }^{\circ} \mathrm{C}$ and $3 \mathrm{MPa}$ was also shown in Fig. 11. It is expected that $\gamma$ of bitumen emulsion also increases linearly with W/O and its slop matches that of heavy oil emulsion.

In conclusion, according to these results, it was found that viscosity alteration strongly depends on W/O ratio and was therefore determined mainly by W/O. Furthermore, $\gamma$ of bitumen emulsion almost agreed with that of heavy oil emulsion.

\section{Construction of Numerical Model for Reservoir Simulation}

In this research, in-situ emulsification was expressed as pseudo reaction using the commercial thermal simulator, CMG STARS ${ }^{\mathrm{TM}}$ (2012) developed to simulate fluid flow in the reservoir for thermal flooding. For instance, when constant W/O ratio in the emulsion generated in the reservoir is assumed as 0.2 , pseudo reaction formula is expressed as:

$$
1(\text { Bitumen })+5.83\left(\mathrm{H}_{2} \mathrm{O}\right) \rightarrow 1 \text { (Emulsion) }
$$

This formula was registered with STARS to express emulsion generation numerically. For the purpose of model development for numerical simulation, the constant $\mathrm{W} / \mathrm{O}(=0.2,0.4$ and 0.6$)$ in the generated emulsions were assumed for simulations respectively. Table 2 shows pseudo reaction formula defined for each emulsification.

Viscosity of each fluid modeled in STARS is given by following Andrade equation that depends on temperature.

$$
\mu=A v i s c \exp \left(\frac{B v i s c}{T}\right)
$$

where,

$\mu$ : apparent viscosity, $\mathrm{cP}$;

$T$ : temperature, $\mathrm{K}$;

Avisc: constant, $\mathrm{cP}$;

Bvisc: constant, $\mathrm{K}$.

According to Taylor's [15] empirical equation, ratio of emulsion viscosity to continuous-phase viscosity is expressed as a linear function of dispersed-phase

Table 2 Emulsion generation models defined by pseudo-reaction formula for each W/O.

\begin{tabular}{ll}
\hline W/O (-) & Pseudo-reaction formula \\
\hline 0.2 & Bitumen $+5.83 \mathrm{H}_{2} \mathrm{O} \rightarrow$ Emulsion \\
0.4 & Bitumen $+11.7 \mathrm{H}_{2} \mathrm{O} \rightarrow$ Emulsion \\
0.6 & Bitumen $+17.5 \mathrm{H}_{2} \mathrm{O} \rightarrow$ Emulsion \\
\hline
\end{tabular}


volume fraction. Again, the experimental result of $\gamma$ vs. $\mathrm{W} / \mathrm{O}$ is represented by sublinear formula at any difference pressures, temperatures and shear rates as shown in Fig. 11. Therefore, the relationship between $\gamma$ and W/O for the heavy oil was represented by following linear formula expressed by following equation.

$$
\gamma=1+2.64 \cdot \mathrm{W} / \mathrm{O}
$$

The constant Avisc of emulsion was defined by multiplying Avisc of original bitumen by $\gamma$ respectively. Thus, the numerical model using Eqs. (2)-(4) is hereinafter called SAGD-Emulsion Model. On the other hand, the model, which does not consider in-situ emulsification, is called Base Model.

In numerical simulations, two dimensional numerical simulations were performed to investigate the effects of viscosity alteration on bitumen production from field scale oil sands reservoir. Scale of the oil sands reservoir was $100.8 \times 1 \mathrm{~m} \times 15 \mathrm{~m}$ and grid system was $201 \times 1 \times 40$. In this model, $215.5{ }^{\circ} \mathrm{C}$ of steam was injected from upper horizontal well, which was located $4.875 \mathrm{~m}$ above the production well as illustrated in Fig. 12. Table 3 shows properties of oil sands reservoir and operation condition that were used for present simulations. These conditions are reservoir properties of Athabasca oil sands used by Souraki et al. [16] for SAGD oil production simulation.

\section{Numerical Simulation Results and Discussion}

The numerical simulation results of three types of SAGD-Emulsion Model (W/O = 0.2, 0.4 and 0.6) were compared with Base Model $(\mathrm{W} / \mathrm{O}=0)$. The comparison of saturation at the steam chamber boundary is shown in Fig. 13. In this figure, grids occupied by steam (saturation $>0.4$ ), connate or condensed water (saturation $>0.4$ ) and emulsion (saturation > 0.4) were represented as steam chamber, water phase and emulsion phase respectively. Other grids were represented as bitumen phase. It has been shown that emulsion was formed at the steam

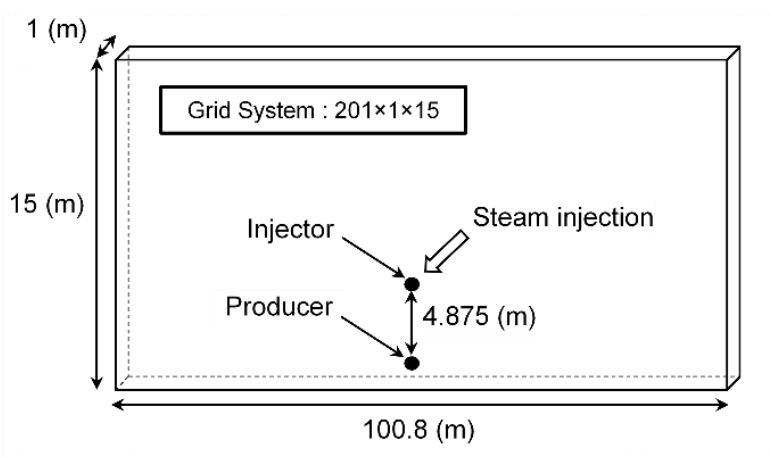

Fig. 12 Field scale numerical simulation model.

Table 3 Properties of Athabasca reservoir and operation condition of steam injection (Ref. [16]).

\begin{tabular}{|c|c|}
\hline Porosity, \% & 38 \\
\hline Horizontal permeability, md & 7000 \\
\hline Vertical permeability, md & 2100 \\
\hline Initial pressure, $\mathrm{kPa}$ & 2068 \\
\hline Initial temperature, ${ }^{\circ} \mathrm{C}$ & 10 \\
\hline Initial water saturation, $\%$ & 20 \\
\hline Initial bitumen saturation, $\%$ & 80 \\
\hline Steam temperature injected, ${ }^{\circ} \mathrm{C}$ & 215.5 \\
\hline Steam quality, $\%$ & 90 \\
\hline Steam injection rate, $\mathrm{m}^{3} /$ day & 0.5 \\
\hline Bottom hole pressure of producer, $\mathrm{kPa}$ & 1700 \\
\hline
\end{tabular}

chamber boundary, especially between gravitational flows of condensed water and heated bitumen.

Fig. 14 shows cumulative oil production of emulsion and bitumen. In SAGD-Emulsion Model, both emulsion and bitumen were produced, but produced emulsion contains some water that depends on the degree of W/O. Net cumulative bitumen production was calculated as shown in Fig. 15. It can be deduced from this figure that the production of SAGD-Emulsion Model was about a month later than that of Base Model. On the other hand, final cumulative oil production was about $5-10 \%$ higher than that of Base Model. These results are attributed to two main reasons: viscosity alteration and swelling. In SAGD-Emulsion Model, viscosity alteration just causes the delay of bitumen production. Bitumen in emulsion, however, flows at high relative permeability because emulsion containing water flows as oil phase (like swelling). In other words, emulsion flow depends on relative permeability and end point values. This assumption agrees with Ezeuko et al. [17]. 

SAGD Considering In-situ Emulsification
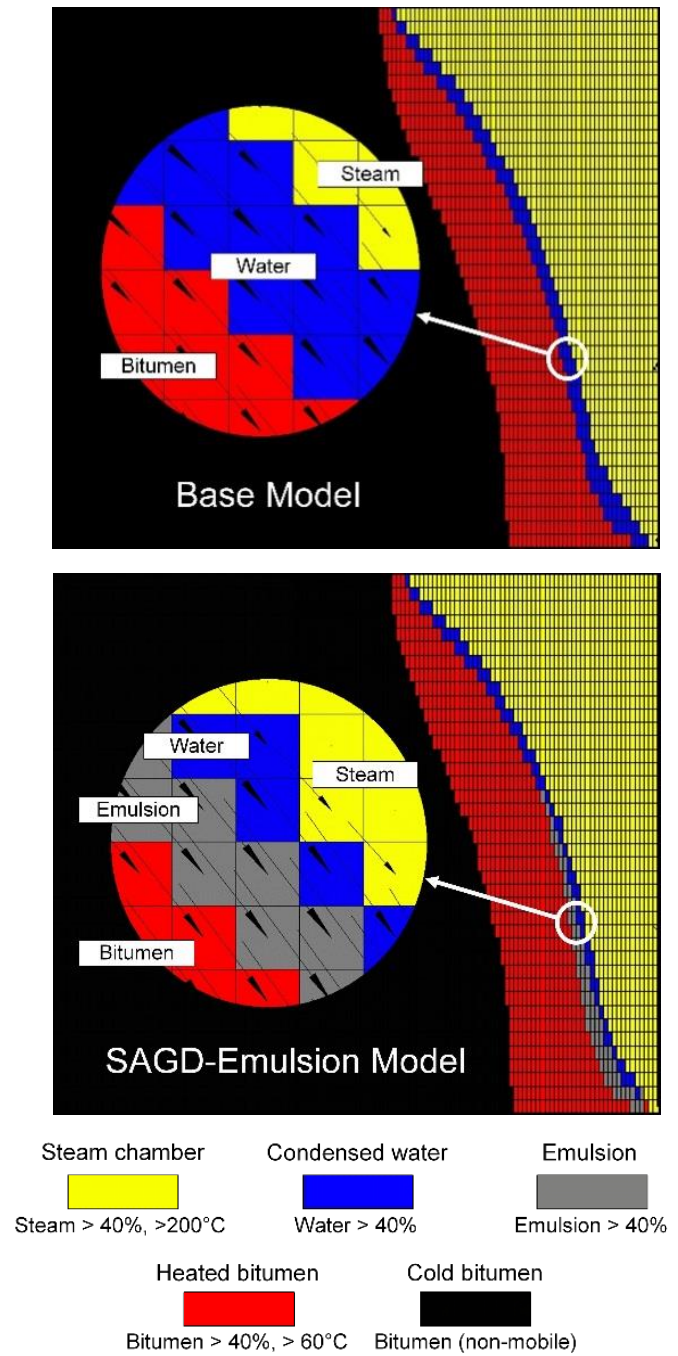

Fig. 13 Comparison of numerical simulation results on fluid saturations at steam chamber boundary (above: Base Model; below: SAGD-Emulsion Model).

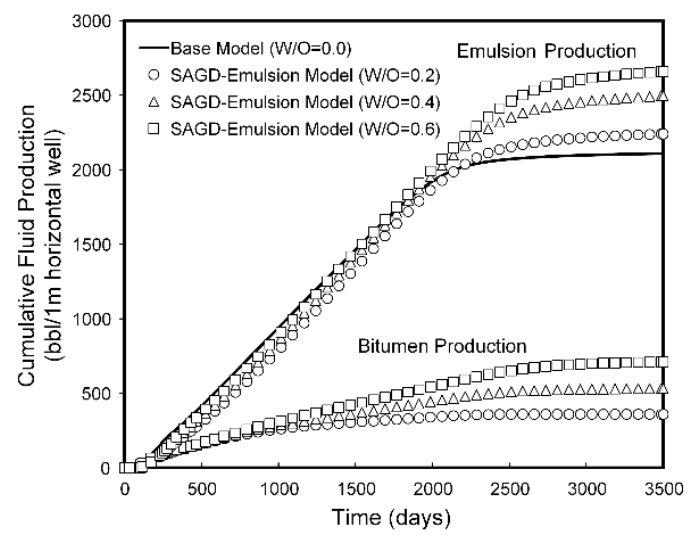

Fig. 14 Comparison of numerical predictions on cumulative bitumen and emulsion production.

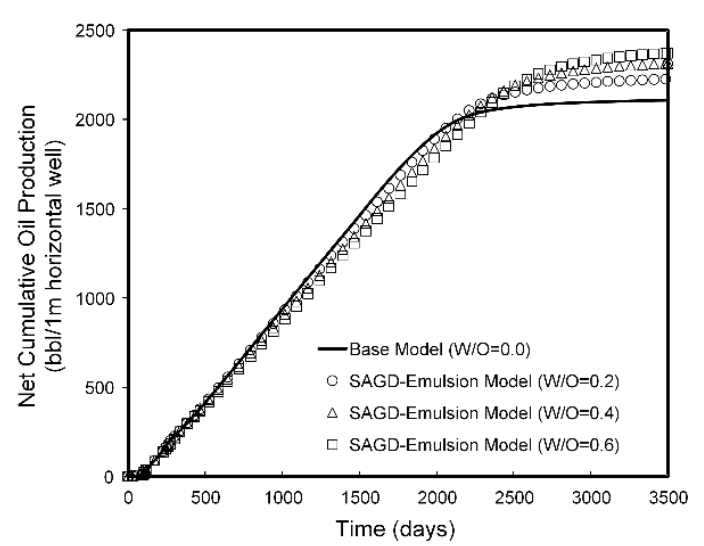

Fig. 15 Comparison of numerical predictions on net cumulative bitumen production.

They also stated that final cumulative production decreased with rise in defined $\mathrm{W} / \mathrm{O}$ because of viscosity increase. Final recovery, however, became larger as W/O became also larger in our conclusion. It is therefore concluded that higher water content in emulsion allows bitumen to flow at higher relative permeability and viscosity increase just causes production delay.

\section{Conclusions}

In this research, viscosity measurements of water-in-oil (W/O) emulsion were carried out to develop a numerical model about viscosity alteration caused by in-situ emulsification. Moreover, effects of in-situ emulsification in a field scale oil sands reservoir on SAGD oil production were investigated by commercial numerical simulator. Specifically, following conclusions were obtained.

(1) Experimental results showed that viscosity increasing ratio $\gamma$, which was defined by the ratio of emulsion viscosity over original oil viscosity, was represented by sublinear formula regardless of shear rates, pressures and temperatures.

(2) The numerical model of viscosity alteration ratio for in-situ emulsification has been presented by Eq. (4) that summarizes the measurement results of heavy oil and bitumen.

(3) Emulsion and condensed water flows at the 

SAGD Considering In-situ Emulsification

steam chamber boundary were expected by the numerical simulations with considering in-situ emulsification. These phenomena were observed in the experimental results presented by Sasaki et al. [3].

(4) Numerical simulation results showed that net recovery factor of bitumen is 5 to $10 \%$ higher by considering in-situ emulsification and the recovery factor increased with water-oil ratio (W/O) in generated emulsions.

(5) The increase in viscosity was expected to induce the delay of production.

\section{Acknowledgments}

The authors would like to acknowledge Japan Petroleum Exploration Co., Ltd. (JAPEX) and Japan Canada Oil Sands Limited (JACOS) for kindly supplying the oil samples used in this study.

\section{References}

[1] Al-Bahlani, A., and Babadagli, T. 2009. "SAGD Laboratory Experiment and Numerical Simulation Studies: A Review of Current Status and Future Issues." Journal of Petroleum Science and Engineering 68: 135-50.

[2] Gates, I. D., and Leskiw, C. 2010. "Impact of Steam Trap Control on Performance of Steam-Assisted Gravity Drainage." Journal of Petroleum Science and Engineering 75: 215-22.

[3] Sasaki, K., Akibayashi, S., Yazawa, N., and Kaneko, F. 2002. "Microscopic Visualization with High Resolution Optical-Fiber Scope at Steam Chamber Interface on Initial Stage of SAGD Process.” In SPE/DOE Improved Oil Recovery Symposium, SPE-75241-MS.

[4] Alade, O. S., Sasaki, K., Sugai, Y., Ademodi, B., Kumasaka, J., and Nakano, M. 2014. "An Aspect of Bitumen Emulsification by Steam Condensation: Effect of Formation Temperature and Bitumen Content." Energy Source, Part A. DOI: 10.1080/15567036.2014.981321, Taylors and Francis (in printing).

[5] Wei, W., Pengyu, W., Kai, L., Jimiao, D., Kunyi, W., and Jing, G. 2013. "Prediction of the Apparent Viscosity of Non-Newtonian Water-in-Crude Oil Emulsions." Petroleum Exploration and Development 40: 130-3.

[6] Chung, K. H., and Butler, R. M. 1987. "Geometrical Effect of Steam Injection on the Formation of Emulsions in the Steam-Assisted Gravity Drainage Process." In SPE
Annual Technical Meeting, PETSOC-87-38-22.

[7] Bennion, D. B., Chan, M., Sarioglu, G., Courtnage, D., Wansleeben, J., and Hirata, T. 1993. "The In-situ Formation of Bitumen-Water Stable Emulsions in Porous Media during Thermal Stimulation.” In SPE International Thermal Operations Symposium, SPE-25802-MS.

[8] Sasaki, K., Akibayashi, S., Yazawa, N., Doan, Q., and Farouq, A. 2001. "Experimental Modeling of the SAGD Process-Enhancing SAGD Performance with Periodic Stimulation of the Horizontal Producer." Society of Petroleum Engineers Journal 6: 89-97.

[9] Sasaki, K., Akibayashi, S., Yazawa, N., Doan, Q., and Farouq, A. 2001. "Numerical and Experimental Modeling of the Steam Assisted Gravity Drainage (SAGD) Process." Journal of Canadian Petroleum Technology 40: 44-50.

[10] Noik, C., Dalmazzone, C., Goulay, C., and Glenat, P. 2005. "Characterization and Emulsion Behavior of Athabasca Extra Heavy Oil Produced by SAGD." In SPE International Thermal Operations and Heavy Oil Symposium, SPE-97748-MS.

[11] Mohammadzadeh, O., and Chatzis, L. 2009. "Pore-Level Investigation of Heavy Oil Recovery Using Steam Assisted Gravity Drainage (SAGD)." In International Petroleum Technology Conference, IPTC-13403-MS.

[12] Maneeintr, K., Sasaki, K., and Sugai, Y. 2013. "Investigation of the Effects of Parameters on Viscosities and Correlation of Heavy Oil and Stability of Its Emulsion." Journal of the Japan Institute of Energy 92: 900-4.

[13] Uzoigwe, A. C., and Marsden, S. S. 1970. "Emulsion Rheology and Flow through Unconsolidated Synthetic Porous Media." In Fall Meeting of the Society of Petroleum Engineers of AIME, SPE-3004-MS.

[14] Alvarado, D. A., and Marsden, S. S. 1979. "Flow of Oil-in-Water Emulsions through Tubes and Porous Media." Society of Petroleum Engineers Journal 19: 369-77.

[15] Taylor, G. I. 1932. "The Viscosity of a Fluid Containing Small Droplets of Another Fluid." Royal Society of London 138: 41-8.

[16] Souraki, Y., Ashrafi, M., Karimaie, H., and Torsaeter, O. 2012. "Experimental Analyses of Athabasca Bitumen Properties and Field Scale Numerical Simulation Study of Effective Parameters on SAGD Performance." Energy and Environment Research 2: 140-56.

[17] Ezeuko, C. C., Wang, J., and Gates, I. D. 2013. "Investigation of Emulsion Flow in Steam-Assisted Gravity Drainage." Society of Petroleum Engineers Journal 18: 440-7. 